Article

\title{
Green Urbanism Embedded in TOD for Urban Built Environment Planning and Design
}

\author{
Wei Huang ${ }^{1}$ and Wann-Ming Wey ${ }^{2, *}$ \\ 1 College of Real Estate, Beijing Normal University, Zhuhai 519085, China; huangwei@bnuz.edu.cn \\ 2 Department of Real Estate and Built Environment, National Taipei University, New Taipei 23741, Taiwan \\ * Correspondence: wmwey@mail.ntpu.edu.tw; Tel.: +886-2-8674-1111 (ext. 67428); Fax: +886-2-8671-530
}

Received: 13 July 2019; Accepted: 19 September 2019; Published: 26 September 2019

\begin{abstract}
Even though the TOD (Transit-Oriented Development) concepts contribute great innovations to our next-generation metropolis, their means and focusing are primarily on the sustainable transportation dimension. It is debatable that the development mode advocated by TOD seems to lack relative considerations of both the ecological and environmental dimensions. Consequently, to achieve a better urban life, our urban planning and design should incorporate the consideration of peripheral areas that have not been further valued in the past, such as ecology diversity, natural energy recycling or reuse, and livable habitat, rather than just focusing on the sustainable transportation dimension of conventional TOD. This study thus explores and summarizes the design criteria of Green TOD through literature review and obtains the evaluation criteria via experts. Furthermore, through the FDT (fuzzy Delphi technique) method, the evaluation criteria from the expert questionnaire are screened. In turn, more important evaluation criteria are obtained objectively. Based on the screening results of FDT, we adopt the HOQ (house of quality) model integrated by FANP (fuzzy analytic network process) and QFD (quality function deployment) to allocate the weighting for each criterion scientifically. Finally, the evaluation results and hybrid decision model provided in this study can be used as an initial reference for improving the planning and design of today's built environment. We believe that these pioneered attempts will help us in attaining our ultimate pursuit of urban sustainability and livability.
\end{abstract}

Keywords: Green TOD; built environment; fuzzy Delphi technique; quality function deployment; fuzzy analytic network process

\section{Introduction}

The TOD concepts embedded in urban transportation planning originated in the U.S. and its systematic functions are expected to replace the initial car-oriented development mode with the transit-oriented development [1] for mitigating urban illness and common transportation dilemma (e.g., the low usage of land resources, high environmental pollution from motor vehicle engines, over-use energy, heavy traffic congestion), and possibly achieving an ideal vision of sustainability [2]. As of now, many American cities such as San Francisco and Atlanta are developed in TOD mode [3]. The urban transportation planning in Asian cities has followed the U.S. for a long time, some local government units in Asia also actively try to confront the urban illness or common transportation dilemma aforementioned by introducing the TOD mode to their major metropolises, such as Taipei City, New Taipei City, Banqiao City, and Kaohsiung City [4-6].

Even though the TOD concepts contribute great innovations to our next-generation metropolises, their means and focus are primarily on the sustainable transportation dimension, for example, high-density land use, diversified mix land use, transit-supportive land uses, as well as friendly street network designs for bicycles and pedestrians [7-10]. However, it is debatable that the development 
mode advocated by TOD seems to lack relative considerations of both the ecological and environmental dimensions. We can reasonably infer that a pure implementation of TOD concepts for urban planning and corresponding artificial construction is inevitably inadequate to facilitate a sustainable, livable, natural, and healthy built environment for our urban life [11,12]. Consequently, to achieve a better urban life, our urban planning and design should incorporate the consideration of peripheral areas that have not been valued in the past, such as ecological diversity, natural energy recycling or reuse, and livable habitat, rather than just focusing on the sustainable transportation dimension of conventional TOD.

On the other hand, the Green TOD, as the critical concept in this study, mainly combines conventional TOD and green urbanism (e.g., [13]) so as to create advanced development modes that maximize the utilization efficiency of resources and energy by environmental design and adopt green building techniques for linking or constructing protected areas, natural ecology, and livable habitats. Such urban construction ideas and development modes not only emphasize a transportation system that has sustainable, balanced, ecological, energy-saving, and so on detail features, but also are additionally connected to the whole built environment of transportation corridor peripheral areas. So, it is worth pondering that if the ecological and environmental dimension can be gradually incorporated into the conventional TOD, which is the so-called Green TOD, then we believe that these advanced development modes as well as pioneered attempts (e.g., $[13,14])$ will help in attaining our ultimate pursuit of urban sustainability and livability $[5,15,16]$.

Based on the motivations and discussions aforementioned, this study is mainly divided into five interlinked segments. Segment 1 of this paper illustrates the motivation for our work. Segment 2 presents the relative information lacking in previous literature and reveals the most important topics concerning this study, such as TOD, GTOD (i.e., Green TOD), green urbanism, and so on. The content revealed and discussed in this section has not only been an ignored subject in government units and past literature, but may also be the main innovation of this study. Segment 3 specifically selects suitable Green TOD criteria through the fuzzy Delphi technique (FDT), that is, the evaluation criteria from the expert questionnaires are screened and more important evaluation criteria are obtained objectively. Based on the screening results of FDT, we adopt the HOQ (house of quality) model integrated by FANP (fuzzy analytic network process) and QFD (quality function deployment) to allocate the weighting for each criterion scientifically. In other words, Segment 4 ranks the priority of the evaluation criteria for conducting built environment planning under the Green TOD. Segment 5 reiterates and explains the main contributions and possible findings from our hybrid decision model designed in this study.

\section{Literature Review}

The definition of the urban built environment is very wide and covers the whole urban environment, which combines human activities, physical designs, and natural environment. Urban development and activities have close relationships with the urban built environment. The construction of the built environment can be conducted through urban design, and Gallion and Eisner they stressed that future urban construction must consider land use, residential housing, the commercial and industrial development, transportation routes, protection, environment pollution, urban disaster prevention, etc. [17] pointed out that urban environment and various facilities form the urban built environment and pointed out that applying a high-density use and a pedestrian-friendly design to transportation corridor peripheral areas will have positive effects on residents' health. Sehatzadeh et al. [18] pointed out that the built environment has impacts on automobile ownership and automobile frequency of use. In their studies, Handy et al. [19] showed that proper development facilities are important to urban built environment and trip behavior, and combined urban design, land use patterns, and transportation systems can facilitate people to walk more and ride a bicycle in order to create a more active, healthy, and livable community environment. Many empirical studies have proven that the built environment has effects on walking behavior and residents' health.

Handy et al. [19] saw the urban built environment as a multiple constructs concept, which includes at least six constructs with interdependent relationships between constructs and dimensions: (1) density 
and intensity, (2) land use mix, (3) street connectivity, (4) street scale, (5) aesthetic qualities, and (6) regional structure. Also, Brownson et al. [20] states that urban built environment affects body movement and urban built environment constructs include both physical aspects and the inner cognition field, the physical part of the built environment affects inner cognition and reflects in body movements. In the study by Brownson et al. [20], the physical part of the built environment could be mainly divided into walking surface, traffic, streetscape, views, and facilities. These five subparts reflect individually in different inner cognitions, such as function, safety, aesthetics, and purpose.

This study mainly explores urban built environment under the Green TOD and the built environment under this situation must have a close relationship with TOD stations; therefore, Rodriguez et al. [21] used items of the built environment and street design to assess and study the relationship between the peripheral areas of train stations and pedestrian activity. Items included: (1) pedestrian-friendly land use and land use mix, (2) setting up a buffer zone between sidewalk and ordinary roadway, (3) the width and quality of pedestrian crossings, and (4) installation of clear location and direction signs. The results proved that the more land-use mixes, the more pedestrian activity; the pedestrian-friendly built environment reflects on the number of pedestrians using the crossing; the width and quality of pedestrian crossing (e.g., the installation of long benches and trash cans) and clear sign designs, etc., are helpful to increase the amount of pedestrian activity and to build a closer relationship between train station and pedestrian activity. Bahareh also analyzed the built environment and the ratio of walking, and classified the built environment into roadway safety, the density of local roads, the density of crossroads, land use mix, and pedestrian-friendly and comfortable street design. In their study of the relationship between the built environment and the safety of pedestrians and bicycle riders, Cho et al. [22] proved that the design of the built environment affects the safety of pedestrians and bicycle riders, and a higher car accident ratio occurred in a high land use mix area where there was no pedestrian-friendly built environment design. In their study, the physical built environment included density, land use mix, street connectivity, path material, and bus transit. Ewing and Cervero [23] pointed out that the classification of the built environment affects urban travel behavior.

One can find from the content above, that the built environment includes constructs that have very wide scopes, and indeed affects peoples' daily life behaviors which, in turn, improve the environmental quality of the city as a whole. One can use the Green TOD concept to construct a design of the built environment around train stations, including land use type, density, building material, plant height, transportation systems and public facilities, and to realize urban built environments with a higher density and stronger and more mixed land use, more open space, pedestrian space, and friendly bicycle systems. Through the formation of a public transportation system to reduce energy consumption, we must be able to provide more friendly communities and more sustainable urban environments [24].

We can find from the literature related to the built environment that it has a very wide scope and affects living quality, the environment, daily behavior pattern, the use of automobiles, and health. The literature also verifies that the planning and design of the built environment affects people (living in an urban area or a community) invisibly and the built environment must be carefully designed and planned if the people living in an urban area or a community want to have a good lifestyle and enjoy superior housing quality.

The Green TOD concept mainly combines TOD and green urbanism to promote environmental design; maximize the utilization efficiency of resources and energy; use green building construction techniques; and develop a city that connects protected area, ecology, and community (e.g., [13]). The Green TOD concept is similar to the TOD concept, hoping to reach urban sustainable development through more concrete methods of development.

Green TOD is derived from the TOD concept. It is a more friendly TOD planning method to the environment. It is learnt from some European urban development patterns (Cervero \& Sullivan, 2010). It adopts sustainable transportation systems and adjusts to the design of surrounding areas. Its final goal is to build a self-sufficient and sustainable urban development. The Green TOD concept mainly 
combines the important elements of TOD and green urbanism. The combination of both realizes the Green TOD possibility in several ways [24]: (1) higher densities, including high population density and higher density housing, to make TOD stations recover their original effectiveness in order to increase the usage and passenger loading rate, as well as to reduce the consumption of renewable energy; (2) mixed land uses: developing from the station and including areas that are built for residential use, commercial purpose, working, shopping, library service, and other daily activities, and use more designed crossways and bicycle routes to increase the use of walking and bicycling, and build green communities around transportation corridor-peripheral areas; (3) reduced surface parking and impervious surfaces: Diasa [25] points out that ground parking spaces will consume half the land resource of many suburban houses, more green urban open space could be created through parking space reduction, and increasing urban permeable surfaces could reduce the heat island effect caused by over-urbanization.

The promotion of TOD is mainly induced by the concept of urban sustainable development, which is a supply-oriented urban development and provides convenient and interconnected urban transportation systems to bring about people, activities, and economics, and to reduce transportation problems caused by AOD (Automobile-Oriented Development)-oriented urban development in the past. The main basic concept of TOD is the 3D built environment introduced by Calthorpe [26], and it is an urban design with the orientation of land use mix, urban tight development, and pedestrian/bicycle. Later, the 5D built environment development pattern was developed because many researchers introduced the 2D concepts to include both the destination accessibility and the distance to transit in the TOD design $[27,28]$.

From the aforementioned literature review, the characteristic of TOD's main built environment introduced in this research adopts the 6D concept: density, diversity, design, destination accessibility, distance to transit, and distinction. These six characteristics are treated as the TOD level criteria in the empirical research.

Green urbanism has been continuously defined differently and vaguely. There was no consensus on the meaning of green urbanism until the book (titled Green Urbanism) introduced by Beatley [29] in the year 2000. The concept of sustainability has become the focal point of urban design during the past 20 years; therefore, Beatley introduces the concept of green urbanism in order to examine the result of sustainable development and to compare the urban design of American cities with that of European cities. Beatley viewed new urbanism as inadequate to solve existing environmental problems. He treated green urbanism as the next step of new urbanism and asserted that the concept of ecologic should be included in the design in order to guide the whole urban development, to form and build more sustainable urban environment and living style. The main target of the green urbanism concept was to reduce the urban ecological foot-prints and to change the extreme relationship between urban and nature. It emphasizes that the cycle of urban metabolism must have the function of auto circulation and metabolism, similar to that of nature ecosystems. The green urbanism concept introduced by Beatley was derived from European urban development patterns; many related design concepts are similar to that of European urban development, whereby the main purpose is to create a people-oriented urban environments, interdependent with natural ecosystems, in order to achieve sustainable development.

The vision of Beatley's green urbanism can be divided into six categories. Lehmann [30] then proposed three visions: (1) the reuse of energy and materials, (2) the protection of water resources and biology variety, (3) the focal of urban planning and transportation planning. These three visions affect the proposed 15 green urbanism principles, including the interrelationship among all urban development related energy, resources, and design. However, the 15 green urbanism principles proposed by Lehmann had a triple-zero framework: (1) zero use of fossil fuel energy, (2) zero waste, including that all buildings can be torn down and be fully recycled for future use, (3) zero emission (target for low carbon emission and zero carbon emission). The triple-zero frameworks can develop full and feasible green urbanism principles. 
Furthermore, Lehmann's 15 green urbanism principles are not totally usable in this research. This research aims to develop the design and planning criteria of urban built environments under the green TOD, so the emphasized construct is the physical built environment construct. The non-physical, or constructs that require large implementation areas, such as food supply chain, educational research and knowledge, and city management do not belong to the scope of this research. The later empirical research paragraphs will construct criteria and delete non-physical constructs, and will explore the criteria of both TOD and the built environment as the basis of building empirical models.

\section{Research Design}

This study conducted urban built environment planning and selection/weighting of designing criteria under the Green TOD through FDT, QFD, and FANP methodologies. The research design model and steps are shown in Figure 1.

Step 1: construct a HOQ of "the built environment and design under the Green TOD", incorporating the requirements of both the urban design for the built environment and the land use restrictions, which are imposed by current laws and regulations, into the HOQ in order to explore whether the Green TOD concept can be incorporated into current laws and regulations, as well as be put into practice in the Asia area.

Step 2: conduct a literature review to explore the criteria factors of built environment planning and design under the Green TOD.

Step 3: examine existing laws and regulations related to built environment planning and design and explore the related laws and regulations that are concerned with the built environment planning and design for the location identified to be the experiment area of this research; these will be seen as the technical requirements of the top side of the HOQ model proposed in this research.

Step 4: through the HOQ model developed in this research, combine FANP to conduct the phase two expert questionnaire in order to obtain the inter-weighting relationship between planning needs and technical requirements; through matrix calculation, obtain the priority weights of the planning need criteria and the existing related laws and regulations for the built environment planning and design - these will be the references for future planning of the built environment of the public transportation corridor peripheral area towards Green TOD concept in Taiwan.

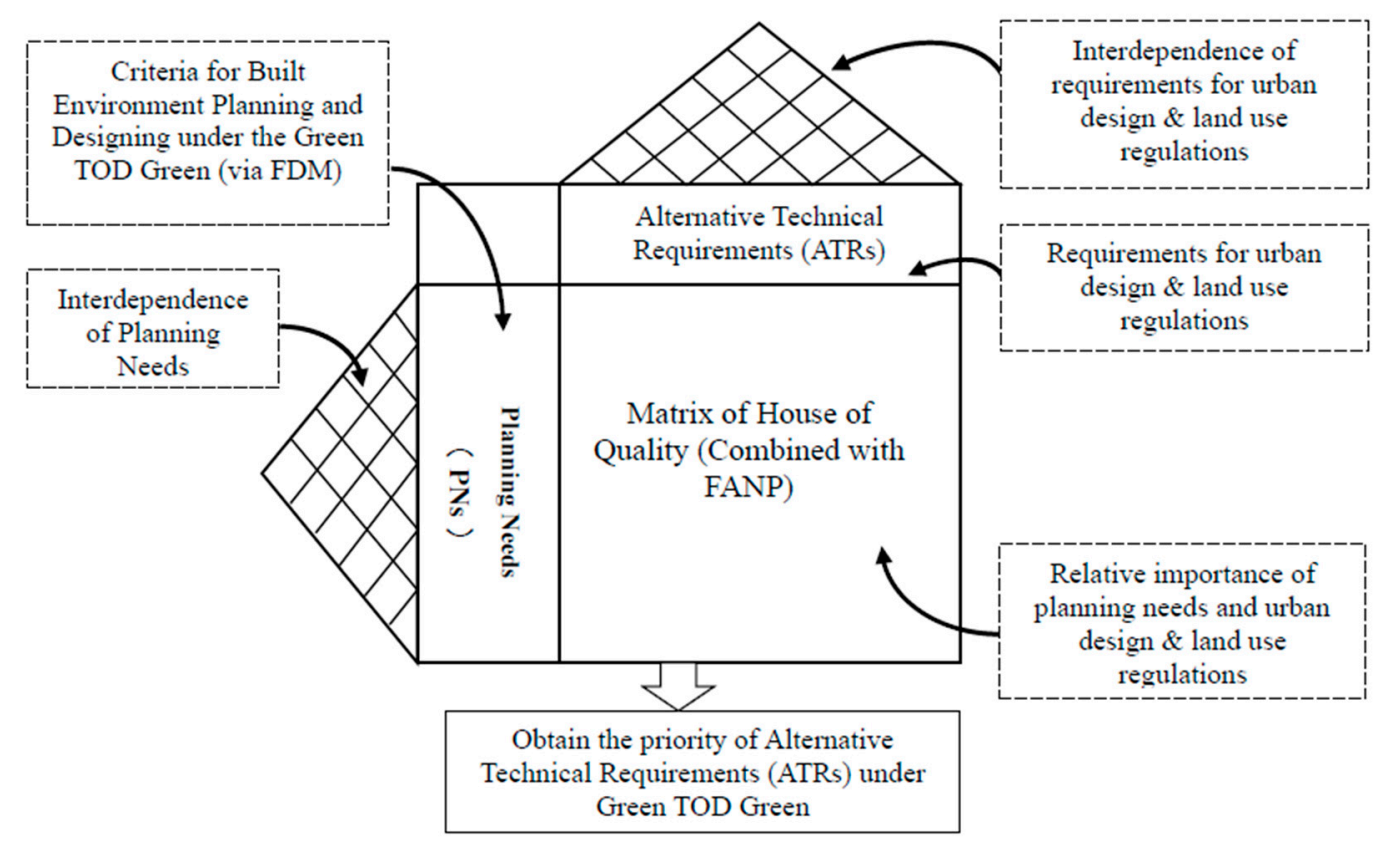

Figure 1. Matrix of house of quality (HOQ) combined with FANP algorithm for the built environment planning and design under the Green TOD. 


\section{Empirical Analysis}

\subsection{Empirical Research Scope}

This research selected the built environment of Taipei rapid transit station (Y18) and its peripheral area, located in the Xinzhuang District of New Taipei City, as the experiment target, the Y18 station corridor peripheral area, which has a large population, can support a proper operation of a metro system and the Xinzhuang District is seen as a future major district in New Taipei City, many preplanning projects have already started and the replanned area requires new construction. Based on the two aforementioned points, these researchers thought that the Xinzhuang District can be developed towards the Green TOD concept, therefore, we selected the built environment of the Y18 station and its peripheral area as experiment target. This research explored the TOD scope under the Green TOD scope. From the literature review, we knew that the suitable scope for TOD is within $500 \mathrm{~m}$-this is a walking distance accepted by pedestrians; moreover, the planned service scope for each metro station in Taipei is also within $500 \mathrm{~m}$. Although the planning concept of this research is Green TOD, this concept is a combination of green urbanism and TOD and is interrelated with TOD, therefore, this research used TOD's suitable scope "the built environment within $500 \mathrm{~m}$ of the Y18 station and its peripheral area" as the study scope of this research.

\subsection{FDT Selects the Built Environment Planning and Design Criteria under the Green TOD}

In order to construct the built environment planning and design criteria under the Green TOD, this research first identified criteria for both TOD and green urbanism through the literature review, then conducted an expert survey, which is designed using the FDT method and selects, "the high density use of urban land" criteria was defined as: using high-density and high-strength land use patterns, combined with land use mix project and flexible special zoning district plans to develop cities, while using the public transportation as the main urban transportation mode. One can include the definition from land use density, land use mix, and low carbon transportation planning, therefore, this research deleted "the high-density use of urban land" criteria before selecting suitable criteria using the FDT method. FDT selects from initial criteria and predefines the consensus threshold as 6.36 in order to select representative criteria, which is based on the steep slope of the criteria trend line.

There were 10 criteria factors above the consensus threshold (6.36); and criteria below the threshold 6.36 were reuse water resources, transit station identity, and zero waste community, these three criteria were deleted.

\subsection{Construct a Built Environment Planning and Design HOQ under the Green TOD}

We combined the built environment planning and design factors and the related laws and regulations (the New Taipei City Urban Design Review Principle and the Xinzhuang District Land-use Control Zoning Regulation) concerned with the built environment planning and design for the studied area in this research to construct a built environment planning and design QFD under the Green TOD. The QFD is shown in Figure 2. The QFD and the expert survey designed using the FANP technique to construct a HOQ model and prioritize the criteria of the built environment planning and design under the Green TOD were integrated. 


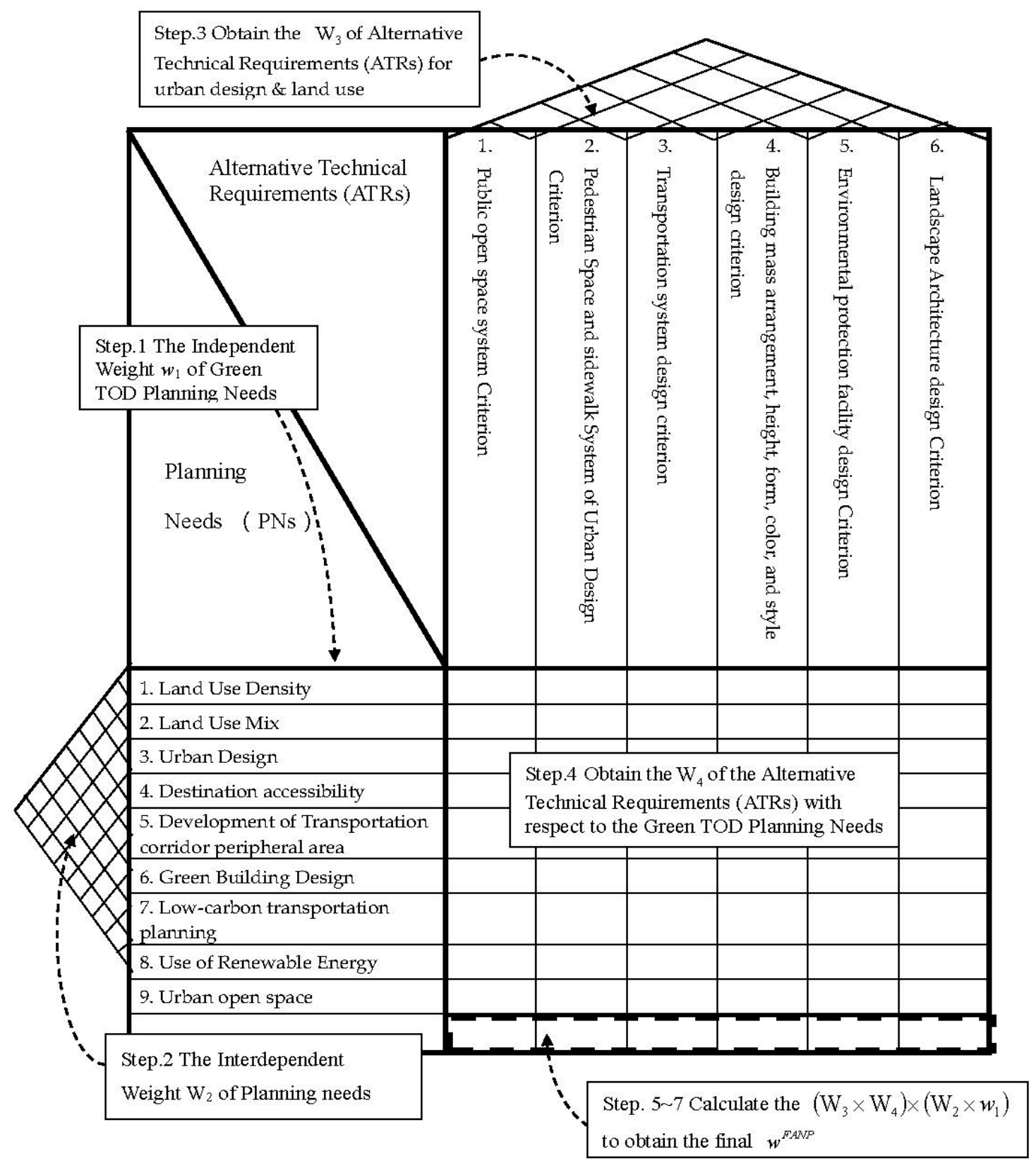

Figure 2. The house of quality (HOQ) matrix for the built environment planning and design under the Green TOD.

\subsection{Prioritize the Criteria of the Built Environment Planning and Design under the Green TOD}

Through the calculation steps of the HOQ matrix, the questionnaire and survey results are described in this section. Through the weight calculation obtained from the expert survey, we were able to obtain the matrix for each step and its interrelated prioritized weights in order to identify the best project and understand the priority of the technique mix required to conduct the built environment planning and design under the Green TOD concept. The survey integration was conducted according to the suggestion given by Satty [31], using the consistency ratio to determine whether experts reached a consensus among their answers; if the CR value was below 0.1 , the paired comparisons in the matrix showed consistency, and the expert survey result was described as follows. 
(1) The independence weight matrix $\left(w_{1}\right)$ of Green TOD planning needs

The independent weight of Green TOD planning needs are the relative weight of Green TOD planning criteria factors in this research and this part was conducted using fuzzy logic. In regards to the built environment planning and design criteria factor under the Green TOD, we asked experts to conduct pairwise comparison and prioritize the importance of criteria factors under no influence. As this part was conducted using the fuzzy logic, the questionnaire asked experts to make comparisons using the ratio scale proposed by Satty, and followed by the defuzzification process whose results will be presented as decimal points.

For the purpose of identifying key planning principles as the important indicators, the first step was choosing the experts group that consisted of urban design, urban planning and engineering, neighborhood organization, community and property management, as well as combining the characteristics of local development units and dwelling users to determine the indicators. The profiles of six experts are shown in Table 1. All of the experts had at least ten years of working and studying experience in urban design and planning and held high-level management positions in urban studies. According to previous research, a sample of size ten to fifteen participants would provide a homogeneous group [32]. Thus, in this study ten questionnaires were sent out to the experts in Taiwan and ten questionnaires were returned with sufficient responses. Furthermore, the questions for the questionnaire also focused on the possible growth management planning principles as mentioned in this research.

Table 1. The Profiles of 6 Experts.

\begin{tabular}{cccc}
\hline Items & Division & Title & Seniority \\
\hline 1 & New Taipei City & Director & 42 \\
2 & New Taipei City & Senior Specialist & 32 \\
3 & Urban Planning Consultant Company & Vice President & 20 \\
4 & Urban Planning Consultant Company & Manager & 15 \\
5 & University Department of Urban Planning and Design & Professor & 22 \\
6 & University Department of Urban Land Administration & Professor & 19 \\
\hline
\end{tabular}

The pairwise comparison results of need criteria are obtained, the eigenvalues of the matrix were one, showing there was an influence value of one when a criterion influences itself, indicating equivalent importance. Using the first row "land use density" as an example, under the "land use density", there is a relative importance score obtained from comparing the "land use density" criteria with each criteria factor. After comparing the nine need factors for planning and designing the built environment under the Green TOD concept, we obtained a weight for each criteria $w_{1}=(0.104741$, $0.193402,0.084714,0.301438,0.153866,0.035949,0.045452,0.023819,0.056620)$, and the CR value is 0.07 showing acceptance, meaning experts reached a consensus among their pairwise comparisons.

$w_{1}=\left[\begin{array}{l}\text { 1. Land Use Density } \\ \text { 2. Land Use Mix } \\ \text { 3. Urban Design } \\ \text { 4. Destination Accessibility } \\ \text { 5. Development of Transportation Corridor Peripheral Area } \\ \text { 6. Green Building Design } \\ \text { 7. Low Carbon Transportation Planning } \\ \text { 8. Use of Renewable Energy } \\ \text { 9. Urban Open Space }\end{array}\right]=\left[\begin{array}{l}0.104741 \\ 0.193402 \\ 0.084714 \\ 0.301438 \\ 0.153866 \\ 0.035949 \\ 0.045452 \\ 0.023819 \\ 0.056620\end{array}\right]$


(2) The interdependence weight matrix $\left(\mathrm{W}_{2}\right)$ of planning need

Comparing the interdependence degree among criteria factors and obtaining the real weights resulting from the influence of criteria on the target, the resulting weights are shown in $W_{2}$.

The interrelated weight matrix $\left(\mathrm{W}_{2}\right)$ of planning need—in addition, each diagonal element Aij $(i=j)$ is the maximum value in a row, showing under this criteria the influence of the criteria on the target reaching its maximum degree. The interrelated weight matrix $\left(\mathrm{W}_{2}\right)$ of planning need is provided below.

$$
\mathrm{w}_{2}=\left[\begin{array}{ccccccccc}
0.374183 & 0.295603 & 0.078308 & 0 & 0.178736 & 0 & 0 & 0 & 0.169036 \\
0.277583 & 0.372436 & 0.113877 & 0.190878 & 0 & 0 & 0.110648 & 0 & 0.263657 \\
0.162116 & 0.048017 & 0.321460 & 0.077801 & 0 & 0 & 0.061550 & 0 & 0.112924 \\
0 & 0.150815 & 0.227307 & 0.423872 & 0.295785 & 0 & 0.248396 & 0 & 0 \\
0.050306 & 0.099880 & 0.166615 & 0.261219 & 0.462929 & 0 & 0.167420 & 0 & 0.072548 \\
0 & 0 & 0.021153 & 0 & 0 & 0.666667 & 0 & 0.093616 & 0 \\
0.030534 & 0.033248 & 0.029419 & 0.04623 & 0.062551 & 0 & 0.364596 & 0.279688 & 0.037063 \\
0 & 0 & 0 & 0 & 0 & 0.333333 & 0.047390 & 0.626696 & 0 \\
0.105278 & 0 & 0.04186 & 0 & 0 & 0 & 0 & 0 & 0.344773
\end{array}\right]
$$

(3) The interdependence weight matrix $\left(\mathrm{W}_{3}\right)$ of technical requirement criteria

This research constructed the interdependence among technical requirement criteria factors and established five interdependence questions in the FANP questionnaire, using this questionnaire to conduct pairwise comparisons for the interdependence among technical requirement specifications, comparing the interdependence degree among criteria factors, and obtaining the real weights resulting from the influence of criteria on the target. All real weights are shown in $W_{3}$.

The interdependence weight matrix $\left(\mathrm{W}_{3}\right)$ of technical requirement criteria-in addition, each diagonal element Aij $(i=j)$ is the maximum value in a row, showing under this criteria the influence of the criteria on the target reaching its maximum degree. The interdependence weight matrix $\left(\mathrm{W}_{3}\right)$ of technical requirement criteria is provided below.

$$
\mathrm{W}_{3}=\left[\begin{array}{cccccc}
0.404337 & 0.299334 & 0.163424 & 0 & 0 & 0.281778 \\
0.306430 & 0.523198 & 0.296961 & 0.352189 & 0 & 0.195374 \\
0.056976 & 0.056506 & 0.539615 & 0 & 0 & 0.055042 \\
0.089142 & 0 & 0 & 0.559065 & 0 & 0.080791 \\
0 & 0 & 0 & 0.088746 & 1 & 0.031996 \\
0.143116 & 0.120962 & 0 & 0 & 0 & 0.355019
\end{array}\right]
$$

(4) $\mathrm{W}_{4}$-the importance degree weight matrix $\left(\mathrm{W}_{4}\right)$ of the technical criteria of the built environment planning and design under the Green TOD concept

This part asked experts, for each Green TOD planning need criteria factor, to rank the importance of each technical requirement specification concerned with current urban design and land use control criteria, in order to obtain the importance degree weight matrix $\left(\mathrm{W}_{4}\right)$ of technical criteria for urban design and land use control, $\mathrm{W}_{4}$ is shown below.

$$
\mathrm{W}_{4}=\left[\begin{array}{ccccccccc}
0.177778 & 0.181818 & 0.209302 & 0.166667 & 0.189189 & 0.136364 & 0.2 & 0.1 & 0.259259 \\
0.177778 & 0.181818 & 0.186047 & 0.266667 & 0.216216 & 0.045455 & 0.24 & 0.2 & 0.222222 \\
0.155556 & 0.136364 & 0.139535 & 0.233333 & 0.216216 & 0.045455 & 0.28 & 0.2 & 0.148148 \\
0.2 & 0.159091 & 0.209302 & 0.1 & 0.135135 & 0.227273 & 0.12 & 0.1 & 0.111111 \\
0.133333 & 0.204545 & 0.069767 & 0.066667 & 0.081081 & 0.318182 & 0.04 & 0.3 & 0.074074 \\
0.155556 & 0.136364 & 0.186047 & 0.166667 & 0.162162 & 0.227273 & 0.12 & 0.1 & 0.185185
\end{array}\right]
$$


(5) The interdependence absolute weight matrix $\left(w_{\mathcal{c}}\right)$ of the need criteria of the built environment planning and design under the Green TOD concept

$w_{1}$, which was obtained from the survey result, is the independence weight matrix $\left(w_{1}\right)$ of need criteria for the built environment planning and design under the Green TOD concept. It is a relative importance degree rather than an absolute weight matrix, and this part has not yet considered the interdependence relationships among criteria factors, therefore, through the calculation of the interdependence degree weight $\left(\mathrm{W}_{2}\right)$ and multiples of the independence weight $\left(w_{1}\right)$, we obtained the interdependence absolute weight $\left(w_{\mathrm{c}}\right)$ of the need criteria of the built environment planning and design under the Green TOD concept, the calculation result is shown below.

$$
\begin{aligned}
& \mathrm{W}_{2} \times w_{1}=w_{c}= \\
& \qquad\left[\begin{array}{l}
0.1400682 \\
0.1882463 \\
0.0861426 \\
0.2329965 \\
0.2003882 \\
0.0279878 \\
0.0610123 \\
0.0290643 \\
0.0340939
\end{array}\right]=\left[\begin{array}{l}
\text { Land Use Density } \\
\text { Land Use Mix } \\
\text { Urban Design } \\
\text { Destination accessibility } \\
\text { Development of Transportation corridor peripheral area } \\
\text { Green Building Design } \\
\text { Low - carbon transportation planning } \\
\text { Use of Renewable Energy } \\
\text { Urban open space }
\end{array}\right]
\end{aligned}
$$

The calculation to obtain the ranking of the weight for the criteria of the built environment planning and design under the Green TOD concept is shown in Table 2. Through this, we know that planning for the built environment within the $500 \mathrm{~m}$ distance of the Y18 station and its peripheral area towards the Green TOD concept emphasizes the importance of the following planning need criteria: destination accessibility (0.2329965), development of transportation corridor peripheral area (0.2003882), and land use mix (0.1882463); there was less emphasis on the importance of green building design and the use of renewable energy. This shows the higher importance of the criteria factors under the TOD construct and less importance of the criteria factors under the Green urbanism construct.

Table 2. The ranking of interdependent weightings for the Green TOD built environment planning and design criteria.

\begin{tabular}{ccc}
\hline Ranking & Planning Need Criteria & Weightings \\
\hline $\mathbf{1}$ & Destination accessibility & 0.2329965 \\
$\mathbf{2}$ & Development of Transportation corridor peripheral area & 0.2003882 \\
$\mathbf{3}$ & Development of Transportation corridor peripheral area & 0.1882463 \\
$\mathbf{4}$ & Land Use Density & 0.1400682 \\
$\mathbf{5}$ & Urban Design & 0.0861426 \\
$\mathbf{6}$ & Low-carbon transportation planning & 0.0610123 \\
$\mathbf{7}$ & Urban open space & 0.0340939 \\
$\mathbf{8}$ & Use of Renewable Energy & 0.0290643 \\
$\mathbf{9}$ & Green Building Design & 0.0279878 \\
\hline
\end{tabular}

(6) $\mathrm{W}_{\mathrm{A}}$-the interdependence absolute weight $\left(\mathrm{W}_{\mathrm{A}}\right)$ of the technical requirement criteria of the New Taipei City Urban Design Review Principle and the Xinzhuang District Land-use Control Zoning Regulations

By multiplying the interdependence weight of technical requirement specification criteria $\left(\mathrm{W}_{3}\right)$ by the importance degree matrix $\left(\mathrm{W}_{4}\right)$ of technical requirement criteria of the built environment planning and design under the Green TOD concept, we obtained the interdependence absolute weight $\left(\mathrm{W}_{\mathrm{A}}\right)$ of the technical requirement criteria of urban design and land-use control. 


$\mathrm{W}_{3} \times \mathrm{W}_{4}=\mathrm{W}_{\mathrm{A}}$
$\quad=\left[\begin{array}{lllllllll}0.194351 & 0.188650 & 0.215546 & 0.232307 & 0.222246 & 0.140212 & 0.232280 & 0.161163 & 0.247739 \\ 0.294513 & 0.274008 & 0.312975 & 0.327663 & 0.314580 & 0.203512 & 0.335710 & 0.249431 & 0.315018 \\ 0.112677 & 0.101723 & 0.107973 & 0.159648 & 0.148596 & 0.047375 & 0.182654 & 0.130426 & 0.117464 \\ 0.140228 & 0.116167 & 0.150702 & 0.084229 & 0.105515 & 0.157578 & 0.094611 & 0.072900 & 0.100191 \\ 0.156060 & 0.223027 & 0.094295 & 0.080874 & 0.098262 & 0.345623 & 0.054489 & 0.312074 & 0.089860 \\ 0.102172 & 0.096426 & 0.118509 & 0.115279 & 0.110801 & 0.105700 & 0.100256 & 0.074006 & 0.129729\end{array}\right.$

(7) The weight $\left(w^{F A N P}\right)$ of the design technical requirement criteria of the built environment planning and design project under the Green TOD concept

Through the step-by-step calculation of HOQ matrices, the need criteria of the built environment planning and design under the Green TOD reflects the weight $\left(w^{F A N P}\right)$ of the design technical requirement criteria of the built environment planning and design project. This can be calculated by multiplying the interdependence absolute weight $\left(\mathrm{W}_{\mathrm{A}}\right)$ of the technical requirement criteria of current urban design and land-use control with the interdependence weight $\left(w_{\mathrm{c}}\right)$ of the need criteria factors of the built environment planning and design under the Green TOD concept.

$$
\begin{aligned}
& \mathrm{W}_{\mathrm{A}} \times w_{\mathrm{c}}=w^{F A N P} \\
& =\left[\begin{array}{l}
0.2111915 \\
0.3033439 \\
0.1314723 \\
0.1109777 \\
0.1356313 \\
0.1073834
\end{array}\right]=\left[\begin{array}{l}
\text { Public open space system Criterion } \\
\text { Pedestrian Space and sidewalk System of Urban Design Criterion } \\
\text { Transportation system design criterion } \\
\text { Building mass arrangement, height, form, color, and style design criterion } \\
\text { Environmental protection facility design Criterion } \\
\text { Landscape Architecture design Criterion }
\end{array}\right]
\end{aligned}
$$

Through the calculation of HOQ matrices to combine the Green TOD planning needs with the technical requirement criteria of current urban design and land-use control, the results show the impact of both planning need preference and expert perception (on the importance degree of design technical requirements) on the technical requirement weight of the built environment planning and design under the Green TOD.

\section{Conclusions}

(1) The proposal of criteria for the built environment planning and design under the Green TOD

Green TOD is a relatively new concept in recent years, few domestic studies have focused on this topic and few researchers have applied this concept to conduct empirical studies in the Asia area, therefore, this research went through the literature review to illustrate the basic theory of Green TOD, separating this into the TOD construct and the green urbanism construct to explore criteria factors. Through the literature review, we identified six criteria under the TOD construct: land use density, land use mix, urban design, destination accessibility, development of transportation corridor peripheral area, and transit station identity; and seven criteria under the green urbanism construct: green building design, zero waste community, the recycle of water resources, low-carbon transportation planning, the use of renewable energy, and urban open space. There were a total of 12 initial factors.

(2) The selection of suitable need factors of the built environment planning and design under the Green TOD for the case study site

The built environment planning will be different with different site locations and the Green TOD concept is derived from TOD, therefore it is more suitable to conduct the built environment planning in the peripheral area of an existing public transportation system or an already planned or an ongoing construction public transportation system. However, not all Green TOD planning need factors are applicable to all built environment planning, therefore we examined the real suitable Green TOD planning need factors for the case study area proposed in this research (the built environment within 
$500 \mathrm{~m}$ of the Y18 station and its peripheral area), this research selected Green TOD planning need initial factors using the FDT method.

Through the calculation result of the FDT expert survey, this research deleted criteria factors that had a value below the threshold of 6.36 , and they were: transit station identity, zero waste community, and the recycle of water resources. Therefore, we could understand the criteria factors that are more applicable to the case study site, "the built environment within $500 \mathrm{~m}$ of the Y18 station and its peripheral area", and they were: land use density, land use mix, urban design, destination accessibility, development of transportation corridor peripheral area, green building design, low-carbon transportation planning, the use of renewable energy, and urban open space.

(3) The identification of the technique requirement for designing the built environment within $500 \mathrm{~m}$ of the Y18 station and its peripheral area towards Green TOD

When planning the built environment for an urban area, the planning must suit one's measures and local conditions, therefore, the planning may need to meet the laws and regulations that govern the selected site location. Thus, this research attempted to combine both the New Taipei City Urban Design Review Principle and the Xinzhuang District Land-use Control Zoning Regulation with the Green TOD built environment planning need criteria. Through the integration of the QFD method (HOQ matrices) and the ANP technique, we calculated both planning needs and technical requirements together, prioritizing the technical requirements that are applicable to Green TOD planning need, and obtaining improvement plans.

This research classified technical requirement criteria based on the New Taipei City Urban Design Review Principle and incorporated the Xinzhuang District Land-use Control Zoning Regulations. Therefore, the technical requirement criteria could be classified into six criteria: public open space system; pedestrian space and sidewalk system of urban design; transportation system design; building mass arrangement, height, form, color, and style design; environmental protection facility design; and landscape architecture design. The final HOQ matrices computation results showed the weight ranking of combining the planning need criteria with the technical requirement criteria, therefore, although the final computation result did not identify any feasible criteria that were included in the need construct, the computation considered them in the prioritization of technical requirement criteria.

(4) The analysis of combining ANP with HOQ matrices

Through the HOQ matrix calculation using the FANP technique of this research, we first calculated and prioritized the absolute weight of the need criteria factors of the built environment planning and design under the Green TOD concept; the computation and ranking results were: (1) land use density (0.2009533), (2) land use mix (0.2221168), (3) urban design (0.1289448), (4) destination accessibility (0.1389202), (5) development of transportation corridor peripheral area (0.1467417), (6) green building design (0.024178), (7) low-carbon transportation planning (0.0820076), (8) the use of renewable energy (0.0230199), and (9) urban open space (0.0331177); one could find that the planning need criteria that were perceived to be more applicable to the case study site were land use mix, land use density, development of transportation corridor peripheral area, and destination accessibility; these four criteria factors were included in the TOD construct, while the criteria factors that are included in the green urbanism construct were less applicable to the case study site.

One could find that through the calculation of HOQ matrix, the combination of the planning need criteria factor with the technical requirement criteria factor showed that HOQ matrices are affected by planning need preferences and expert perceptions of the importance degree of the technical requirement criteria of the built environment design under the Green TOD concept. The weights of technical requirement criteria were: (1) public open space system (0.1843312); (2) pedestrian space and sidewalk system of urban design (0.3051524); (3) transportation system design (0.172987); (4) building mass arrangement, height, form, color, and style design (0.0920303); (5) environmental protection facility design (0.1546468); and (6) landscape architecture design (0.0908523). Among these criteria, 
the pedestrian space and sidewalk system of urban design criterion was perceived by experts as the most important criteria; the second-most important criteria were the public open space system criterion and the transportation system design; and the following ranking were the environmental protection facility design criterion; building mass arrangement, height, form, color and style design criterion; and the landscape architecture design criterion.

The approach applied the FDT, FANP, and QFD to model the inner and outer dependences between the criteria in the matrix. Based on the prioritization of the growth management principle weightings, the relative importance of principles was determined. Finally, given these relative importance degrees, the future strategies application was utilized to consider both environmental and sustainable planning requirements. These technical requirements are viewed as feasible and important criteria for designing future urban built environment planning and design strategy. The proposed approach not only identifies the green urbanism embedded in TOD, but also finds hidden causal relationships between physical components and user's needs. The paper illustrates the proposed approach in an empirical study in Xinzhuang District of New Taipei City, showing the proposed approach is a valuable tool for planners. The approach enables urban planners to identify the features of important environment constructs and to output some important information when testing the present structure of urban planning and design evaluation in sustainable urban built environmental planning. In doing so, planners will be able to select the best strategy option to make an effective decision. In other words, through our empirical study, planners will be able to consider end-use needs when inputting necessary planning elements to improve the sustainable urban built environment planning strategies for quality of life in New Taipei City and increase user satisfaction by utilizing output information generated from the modeling process.

Author Contributions: All authors contributed to studying and writing this article. Further, they have all read and approved the final manuscript.

Funding: This research received no external funding.

Acknowledgments: The authors would like to thank anonymous referees and the Editor of the journal for constructive comments and suggestions. The authors also wish to acknowledge Yen-Hsiang Wen for her participation in data collection and analysis activities.

Conflicts of Interest: The authors declare no conflict of interest.

\section{References}

1. Newman, P.; Kenworthy, J. The End of Automobile Dependence: How Cities Are Moving Beyond Car-Based Planning; Island Press: Washington, DC, USA, 2015.

2. Wey, W.M. A Commentary on Sustainably Built Environments and Urban Growth Management. Sustainability 2018, 10, 3898. [CrossRef]

3. Sung, H.; Oh, J.T. Transit-oriented development in a high-density city: Identifying its association with transit ridership in Seoul, Korea. Cities 2011, 28, 70-82. [CrossRef]

4. Wey, W.M.; Zhang, H.; Chang, Y.J. Alternative transit-oriented development evaluation in sustainable built environment planning. Habitat Int. 2016, 55, 109-123. [CrossRef]

5. Wey, W.M.; Huang, J.Y. Urban sustainable transportation planning strategies for livable City's quality of life. Habitat Int. 2018, 82, 9-27. [CrossRef]

6. Wey, W.M. Constructing urban dynamic transportation planning strategies for improving quality of life and urban sustainability under emerging growth management principles. Sustain. Cities Soc. 2019, 44, 275-290. [CrossRef]

7. Cervero, R.; Kockelman, K. Travel demand and the 3Ds: Density, diversity, and design. Transp. Res. Part D Transp. Environ. 1997, 2, 199-219. [CrossRef]

8. Wey, W.M.; Chiu, Y.H. Assessing the walkability of pedestrian environment under the transit-oriented development. Habitat Int. 2013, 38, 106-118. [CrossRef]

9. Park, K.; Ewing, R.; Scheer, B.C.; Tian, G. The impacts of built environment characteristics of rail station areas on household travel behavior. Cities 2018, 74, 277-283. [CrossRef] 
10. Stojanovski, T. Urban design and public transportation-Public spaces, visual proximity and Transit-Oriented Development (TOD). J. Urban Des. 2019, 1-21. [CrossRef]

11. Yigitcanlar, T.; Teriman, S. Rethinking sustainable urban development: towards an integrated planning and development process. Int. J. Environ. Sci. Technol. 2015, 12, 341-352. [CrossRef]

12. Zhan, D.; Kwan, M.P.; Zhang, W.; Fan, J.; Yu, J.; Dang, Y. Assessment and determinants of satisfaction with urban livability in China. Cities 2018, 79, 92-101. [CrossRef]

13. Cervero, R.; Sullivan, C. Green TODs: Marrying transit-oriented development and green urbanism. Int. J. Sustain. Dev. World Ecol. 2011, 18, 210-218. [CrossRef]

14. Motieyan, H.; Mesgari, M.S. A novel spatial index using spatial analyses and hierarchical fuzzy expert system for obtaining green TOD: a case study in Tehran city. Geocarto Int. 2019, 34, 1-22. [CrossRef]

15. Bettencourt, L.; West, G. A unified theory of urban living. Nature 2010, 467, 912. [CrossRef] [PubMed]

16. Huang, J.Y.; Wey, W.M. Application of Big Data and Analytic Network Process for the Adaptive Reuse Strategies of School Land. Soc. Indic. Res. 2019, 142, 1075-1102. [CrossRef]

17. Frank, L.D.; Schmid, T.L.; Sallis, J.F.; Chapman, J.; Saelens, B.E. Linking objectively measured physical activity with objectively measured urban form. Am. J. Prev. Med. 2005, 28, 117-125. [CrossRef] [PubMed]

18. Sehatzadeh, B.; Noland, R.B.; Weiner, M.D. Walking frequency, cars, dogs, and the built environment. Transp. Res. Part A 2011, 45, 741-754. [CrossRef]

19. Handy, S.L.; Boarnet, M.G.; Ewing, R.; Killingsworth, R.E. How the built environment affects physical activity: views from urban planning. Am. J. Prev. Med. 2002, 23, 64-73. [CrossRef]

20. Brownson, R.C.; Hoehner, C.M.; Day, K.; Forsyth, A.; Sallis, J.F. Measuring the Built Environment for Physical Activity. Am. J. Prev. Med. 2009, 36, S99-S123. [CrossRef]

21. Rodriguez, D.A.; Brisson, E.M.; Estupiñán, N. The relationship between segment-level built environment attributes and pedestrian activity around Bogota's BRT stations. Transp. Res. Part D Transp. Environ. 2009, 14, 470-478. [CrossRef]

22. Cho, G.; Rodriguez, D.A.; Khattak, A.J. The role of the built environment in explaining relationships between perceived and actual pedestrian and bicyclist safety. Accid. Anal. Prev. 2009, 41, 692-702. [CrossRef] [PubMed]

23. Ewing, R.; Cervero, R. Travel and the built environment: A synthesis. Transp. Res. Rec. 2001, 1780, 87-114. [CrossRef]

24. Cervero, R.; Sullivan, C. Toward Green TODs; Working paper; UC Berkeley Center for Future Urban Transport: Berkeley, CA, USA, 2010.

25. Daisa, J. Traffic, Parking, and Transit Oriented Development. In The New Transit Town: Best Practices in Transit-Oriented Development; Dittmar, H., Ohland, G., Eds.; Island Press: Washington, DC, USA, 2004; pp. 114-129.

26. Calthorpe, P. The Next American Metropolis: Ecology, Community, and the American Dream; Princeton Architectural Press: New York, NY, USA, 1993.

27. Cervero, R.; Murakami, J. Rail+Property Development in Hong Kong; MTR Corporation: Hong Kong, 2008.

28. Hamin, E.M.; Gurran, N. Urban form and climate change: Balancing adaptation and mitigation in the U.S. and Australia. Habitat Int. 2009, 33, 238-245. [CrossRef]

29. Beatley, T. Green Urbanism: Learning from European Cities; Island Press: Washington, DC, USA, 2000.

30. Lehmann, S. The Principles of Green Urbanism: Transforming the City for Sustainability; Earthscan: London, UK, 2010.

31. Saaty, T.L. Decision Making with Dependence and Feedback: The Analytic Network Process; RWS: Pittsburgh, PA, USA, 1996.

32. Hwang, C.L.; Lin, M.J. Group Decision Making under Multiple Criteria: Methods and Applications; Springer: Berlin, Germany, 1987.

(C) 2019 by the authors. Licensee MDPI, Basel, Switzerland. This article is an open access article distributed under the terms and conditions of the Creative Commons Attribution (CC BY) license (http://creativecommons.org/licenses/by/4.0/). 